\title{
Mesoporous bioactive glass surface modified poly(lactic-co-glycolic acid) electrospun fibrous scaffold for bone regeneration
}

This article was published in the following Dove Press journal:

International Journal of Nanomedicine

2 June 2015

Number of times this article has been viewed

\author{
Shijie Chen, ${ }^{1, *}$ Zhiyuan Jian, ${ }^{2, *}$ \\ Linsheng Huang, ${ }^{2, *}$ Wei $\mathrm{Xu},{ }^{3, *}$ \\ Shaohua Liu, ${ }^{4}$ Dajiang Song, ${ }^{3}$ \\ Zongmiao Wan, ${ }^{3}$ Amanda \\ Vaughn, ${ }^{5}$ Ruisen Zhan, ${ }^{1}$ \\ Chaoyue Zhang,' Song Wu,' \\ Minghua $\mathrm{Hu},{ }^{6}$ Jinsong $\mathrm{Li}^{1}$ \\ 'Department of Orthopaedics, The \\ Third Xiangya Hospital of Central South \\ University, Changsha, Hunan, People's \\ Republic of China; ${ }^{2}$ The First General \\ Surgery Department of Shiyan Taihe \\ Hospital Affiliated to Hubei University \\ of Medicine, Shiyan, People's Republic \\ of China; ${ }^{3}$ Department of Orthopedic \\ Oncology, Changzheng Hospital, The \\ Second Military Medical University, \\ Shanghai, People's Republic of China; \\ ${ }^{4}$ Department of Spine Surgery, Xiangya \\ Hospital of Central South University, \\ Changsha, Hunan, People's Republic \\ of China; ${ }^{5}$ Department of Molecular \\ Biosciences, Institute of Cellular and \\ Molecular Biology, The University \\ of Texas at Austin, Austin, TX, USA; \\ ${ }^{6}$ Department of Anthropotomy, \\ Changsha Medical College, Changsha, \\ Hunan, People's Republic of China \\ *These authors contributed equally \\ to this work
}

Correspondence: Jinsong Li Department of Orthopaedics, The Third Xiangya Hospital of Central South University, Changsha, Hunan, 4I00I3, People's Republic of China Tel +86 73I 886I 8026

Email jinsongli. 1982@gmail.com

Minghua $\mathrm{Hu}$

Department of Anthropotomy, Changsha Medical College, Changsha, Hunan, 410219, People's Republic of China Tel +86 73I 88808731

Email I I Itiger@sina.com

\begin{abstract}
A mesoporous bioactive glass (MBG) surface modified with poly(lactic-co-glycolic acid) (PLGA) electrospun fibrous scaffold for bone regeneration was prepared by dip-coating a PLGA electrospun fibrous scaffold into MBG precursor solution. Different surface structures and properties were acquired by different coating times. Surface morphology, chemical composition, microstructure, pore size distribution, and hydrophilicity of the PLGA-MBG scaffold were characterized. Results of scanning electron microscopy indicated that MBG surface coating made the scaffold rougher with the increase of MBG content. Scaffolds after MBG modification possessed mesoporous architecture on the surface. The measurements of the water contact angles suggested that the incorporation of MBG into the PLGA scaffold improved the surface hydrophilicity. An energy dispersive spectrometer evidenced that calcium-deficient carbonated hydroxyapatite formed on the PLGA-MBG scaffolds after a 7-day immersion in simulated body fluid. In vitro studies showed that the incorporation of MBG favored cell proliferation and osteogenic differentiation of human mesenchymal stem cells on the PLGA scaffolds. Moreover, the MBG surface-modified PLGA (PLGA-MBG) scaffolds were shown to be capable of providing the improved adsorption/release behaviors of bone morphogenetic protein-2 (BMP-2). It is very significant that PLGA-MBG scaffolds could be effective for BMP-2 delivery and bone regeneration.
\end{abstract}

Keywords: mesoporous, scaffolds, bone regeneration, stem cells, BMP-2

\section{Introduction}

Bone tissue is important for its structural, protective, and support roles, while it is also a mineral reservoir that facilitates movement. ${ }^{1}$ As a dynamic tissue, it constantly continues to self-repair throughout life without scarring. ${ }^{2}$ However, severe injury calls for artificial bone alternatives. Many promising materials have been proposed that can compensate for a lack of bone donors and minimize rejection concerns common to allografts and xenografts..$^{3,4}$

One of the most important elements involved in the design of bone repair materials is biocompatibility. ${ }^{5,6}$ Biocompatibility of bone grafts can be subdivided into composition and structure biocompatibility, which are based on the selection and design of the materials, respectively. Composition biocompatibility is a function of the surface chemistry of the scaffold. Cell adhesion, migration, and other activities may be modulated by the surface adsorbed biomolecules associated with the chemical characteristics of materials. ${ }^{7,8}$ Thus, the proper bone materials must be selected carefully. The proper transport of nutrients and maintenance of homeostasis are critical.

There are many approaches to building bone scaffolds, but electrospinning is very simple and produces highly porous $(90 \%)$ products that offer interconnected pores 
and nanoscale matrix features. It has been evidenced that nanofibers can regulate cellular behavior by stimulating cell proliferation and differentiation. In fact, cells are likely to attach and organize around fibers with diameters smaller than that of the cell itself. ${ }^{9}$ Furthermore, it has been shown that phenotypic markers cannot be expressed if the fiber diameter of scaffold is equivalent to, or larger than, the cell. ${ }^{10}$

One ideal material is poly(lactic-co-glycolic acid) (PLGA), ${ }^{11}$ which is US Food and Drug Administration (FDA) approved, ${ }^{12}$ biocompatible, and bioresorbable. ${ }^{13}$ The ester group on the molecular chain of PLGA can hydrolyze. Its byproducts are lactic acid and glycolic acid, which can be metabolized and cleared. For these reasons, we used PLGA electrospun nanofibers in the current study. Electrospinning has been used since the early 1930s, and offers a non-woven, three-dimensional, porous, and nanoscale, fiber-based matrix. ${ }^{14-16}$ It creates ultrafine fibers by electrically charging a suspended droplet of melted polymer or polymer solution, and PLGA fibrous scaffolds created through electrospinning are similar to the natural extracellular matrix (ECM). ${ }^{17,18}$

Limitations to PLGA include a lack of hydrophilicity, bioactivity, ${ }^{19-21}$ and a compromised mechanical strength. ${ }^{22,23}$ In addition, the release of the byproducts of acidic degradation of PLGA implants can decrease the $\mathrm{pH},{ }^{24,25}$ which may lead to inflammation. One solution is to use inorganic materials such as hydroxyapatite (HAp), ${ }^{26,27} \beta$-tricalcium phosphate $\left(\beta\right.$-TCP), ${ }^{28-30}$ and bioactive glass $(\mathrm{BG}) .{ }^{24,31,32}$ All of these have been incorporated into PLGA for inorganic/organic composites. BG improves bioactivity and is more effective at stabilizing $\mathrm{pH}$ compared to HAp. BG can release $\mathrm{Ca}$ and $\mathrm{Si}$ ionic products, which are able to neutralize byproducts of acidic degradation of PLGA. ${ }^{33}$ Mesoporous bioactive glass (MBG), with pore sizes ranging from 2 to $50 \mathrm{~nm}$, has a large surface area and pore volume. Meanwhile, it offers superior bioactivity versus non-mesoporous BG. ${ }^{34}$ Moreover, MBG stimulates the formation and deposition of calcium phosphates from a physiological solution. ${ }^{35,36}$ This promotes the differentiation and proliferation of osteoblasts, ultimately causing the bone matrix interface to strengthen. ${ }^{37,38}$ These features give MBG superior bioactivity and make it a leading candidate for drug or protein delivery. One good example is bone morphogenetic protein-2 (BMP-2), which is a potent inducer of bone formation that has been used clinically for over 10 years. ${ }^{39}$ It has also been used in non-union, open fractures, joint fusions, aseptic bone necrosis, and critical bone defects. ${ }^{40}$ Moreover, MBG was shown to be capable of increasing adsorption and providing sustained release of BMP-2. ${ }^{41,42}$
The use of MBG in addition to PLGA fibrous scaffolds prevents the limitations that arise from using electrospun PLGA fibrous scaffolds alone for bone defect repairs. For instance, it stabilizes the $\mathrm{pH}$ of the surrounding environment, improves the bioactivity and hydrophilicity of PLGA scaffolds, and increases the drug loading and delivery capacity. ${ }^{33-36}$ Therefore, MBG particles had been blended into the PLGA solution and further electrospun to produce the MBG composite PLGA fibrous scaffolds. ${ }^{43}$ However, the distribution of $\mathrm{MBG}$ in the electrospun PLGA fibers is often not very uniform, and the mesoporous structure of MBG embedded in PLGA might be blocked. In the present study, we wanted to mimic the major ECM of bone while enhancing the mechanical properties and biological response of the scaffolds. This is the first report, to the best of our knowledge, to use a dip-coating method to uniformly assemble MBG onto the surface of the electrospun PLGA nanofibers. The combination of the microstructure of bioactive inorganic phase with the chemical property of the synthetic biopolymers could offer synergistic advantages in mechanical properties, degradation stability, cell affinities, and drug delivery. Therefore, the objective of this study was to fabricate an MBG surface-modified PLGA electrospinning fibrous scaffold that mimicked the structure of the ECM and favored bone regeneration. Herein, we characterize the microscopic and macroscopic structures of the composite scaffold, in addition to its biocompatibility, and recapitulate osteogenesis in vitro. Furthermore, we explore the composite scaffold potential as a BMP-2 delivery system.

\section{Materials and methods Preparation of PLGA and PLGA-MBG membranes}

The nanofibrous membranes were fabricated by the following electrospinning technique. Firstly, PLGA was homogeneously dissolved in hexafluoroisopropanol (HFIP), forming a $10 \%$ wt solution. The polymer solution was electrospun with a syringe equipped with a 22 gauge steel needle using a $24.5 \mathrm{kV}$ potential, with a tip-to-collector distance of $15 \mathrm{~cm}$, and a syringe flow rate of $1 \mathrm{~mL} / \mathrm{h}$ at room temperature. An aluminum foil-wrapped collector plate was used to form the porous fibrous films. The nanofibers were then dried in a $37^{\circ} \mathrm{C}$ vacuum for 12 hours to remove residual HFIP.

The MBG precursor solution was prepared by using P123 $\left(\mathrm{EO}_{20} \mathrm{PO}_{70} \mathrm{EO}_{20}\right)$ according to a previous report. ${ }^{44}$ Briefly, P123 (number-average molecular weight (Mn) 5,800; Sigma-Aldrich Co, St Louis, MO, USA, 4.0 g), tetraethyl 
orthosilicate (6.7 g), $\mathrm{Ca}\left(\mathrm{NO}_{3}\right)_{2} \cdot 4 \mathrm{H}_{2} \mathrm{O}(1.4 \mathrm{~g})$, triethyl phosphate $(0.73 \mathrm{~g})$, and $0.5 \mathrm{M} \mathrm{HCl}(1.0 \mathrm{~g})$ were dissolved in ethanol $(60 \mathrm{~g})$ and stirred at room temperature for 1 day. The PLGA film was then immersed in the solution for 10 minutes. It was then transferred to a Petri dish, and the excess solution was removed with centrifugation (10 minutes, 1,000 rpm). Additional solution was evaporated at room temperature for 24 hours. This coating step was repeated 2,4 , or 8 times. The resulting scaffolds were termed $\mathrm{P} 2, \mathrm{P} 4$, or $\mathrm{P} 8$, respectively. In comparison, the unmodified PLGA film was named P0. When completely dried, the samples were extracted with absolute ethyl alcohol containing $1 \mathrm{vol} \% \mathrm{HCl}(37 \mathrm{wt} \%)$ at $37^{\circ} \mathrm{C}$ for 24 hours. The extracting solution was changed every 8 hours in order to extract as much P123 as possible.

\section{Scaffold characterization}

The surface morphology of the scaffolds was analyzed with scanning electron microscopy (SEM) (JSM-6700F; JEOL, Tokyo, Japan) at an acceleration voltage of $25 \mathrm{kV}$; before SEM observation, all of the samples $(1 \mathrm{~cm} \times 1 \mathrm{~cm})$ were sputter coated with gold for 60 seconds. The fiber diameter and the pore size $(n=10)$ were measured by ImageJ software. The elemental composition of the P8 film surface was evaluated using an energy dispersive spectrometer (EDS) connected to the SEM instrument. The mesopore-channel microstructure of the P8 scaffold was characterized with transmission electron microscopy (TEM) (JEOL 2010; JEOL). The $\mathrm{N}_{2}$ adsorption-desorption isotherms were obtained using a Micromeritics porosimeter (TriStar 3000; Micromeritics, Norcross, GA, USA) at $77 \mathrm{~K}$, using continuous adsorption. The Brunauer-Emmett-Teller and Barrett-Joyner-Halenda techniques ${ }^{45}$ determined the surface area, pore size, and pore volume. A static contact angle measurement system determined the hydrophilicity of the scaffold surface. Approximately $1 \mu \mathrm{L}$ of water was dropped on the top surface of the films, and the contact angle measurement was made after a static time of 30 seconds. In total, we used five scaffolds and six data points for the mean and standard deviation (SD) calculations.

\section{Bioactivity analysis}

We next prepared the simulated body fluid (SBF). ${ }^{46}$ Film samples $(\mathrm{n}=3)$ were soaked in $50 \mathrm{~mL} \mathrm{SBF}$ solutions at $37^{\circ} \mathrm{C}$ with $100 \mathrm{rpm}$ shaking. After 7 days, the specimens were removed and rinsed with distilled deionized (DDI) water and then dried overnight at $37^{\circ} \mathrm{C}$. The mineral elements formed on the surface at day 7 were analyzed with EDS (JSM-6700F).

\section{Cell culture}

Human mesenchymal stem cells (hMSCs) (ScienCell Research Laboratories, San Diego, CA, USA) were cultured in Minimum Essential Medium Eagle-alpha modification ( $\alpha$-MEM) culture medium supplemented with $20 \%$ fetal bovine serum (FBS), $1 \%$ penicillin $(100 \mathrm{U} / \mathrm{mL})$, and streptomycin sulphate $(100 \mu \mathrm{g} / \mathrm{mL})$ (GibcoBRL, Grand Island, NY, USA). The cells were incubated at $37^{\circ} \mathrm{C}$ in a $5 \% \mathrm{CO}_{2}$ incubator. The media was changed every 2 days. The hMSCs at passage 3 were detached with $0.25 \%$ trypsin, washed, and used as needed.

\section{Cell proliferation}

Cell suspension containing $2 \times 10^{4}$ cells $(1 \mathrm{~mL})$ was seeded onto the different samples in a 48-well plate. After 1,3, and 5 days' culture, cell proliferation of hMSCs on the different substrates was examined via MTT (Beyotime Institute of Biotechnology, Shanghai, People's Republic of China), respectively. ${ }^{47}$ Briefly, $0.1 \mathrm{~mL}$ of MTT solution $(5 \mathrm{mg} / \mathrm{mL}$ in Hank's balanced salt solution) was added to each well and incubated at $37^{\circ} \mathrm{C}$ for 4 hours at each time point. After removal of the medium, the reduction product, formazan of MTT, was dissolved with dimethyl sulfoxide. Finally, $200 \mu \mathrm{L}$ of the dissolved solution was transferred to a 96-well plate and measured by a plate reader (Synergy ${ }^{\mathrm{TM}} \mathrm{HT}$; Biotek Instruments, Winooski, VT, USA) at $570 \mathrm{~nm}$. Experiments were performed in replicates of five.

\section{Osteogenic differentiation of hMSCs}

The hMSCs were differentiated into an osteogenic lineage to test for effects of the substrate. The hMSCs $\left(3 \times 10^{4}\right.$ cells $\left./ \mathrm{mL}\right)$ were firstly incubated in a 48 -well plate with four substrates for 24 hours. The culture medium was then changed to the osteogenic induction medium (OIM). This was prepared from an $\alpha$-MEM culture medium with $10 \%$ FBS, $0.1 \mu \mathrm{M}$ dexamethasone (Sigma-Aldrich Co), $50 \mu \mathrm{M}$ ascorbic acid (Sigma-Aldrich Co), and $10 \mathrm{mM} \beta$-glycerophosphate sodium (Sigma-Aldrich Co). This medium was changed every 2 days. At 3, 7, and 14 days of culture with OIM, the alkaline phosphatase (ALP) activity was determined with p-nitrophenyl phosphate (pNPP; Sigma-Aldrich Co) as the substrate. The total protein content was also measured using a Bradford protein assay (BSA). Briefly, ALP activities were measured with an ALP reagent and pNPP as the substrate. The absorbance of the pNPP was measured at $405 \mathrm{~nm}$. The intracellular protein content was measured with a Micro $\mathrm{BCA}^{\mathrm{TM}}$ protein assay kit; ALP activity was normalized to the BCA data. 
After 14 days, the ALP staining was performed. The cells on the membranes were detached with $100 \mu \mathrm{L}$ of $0.25 \%$ trypsin, and transferred to another 48-well plate containing $1 \mathrm{~mL}$ culture medium. The cells were allowed to adhere to the surface of the plate. After 24 hours, the cells had spread along the bottom of the well, and were then washed twice with phosphate-buffered saline (PBS), and fixed for 30 seconds with buffered formalin as described in the ALP staining kit instructions (Beyotime Biotech, Jiangsu, People's Republic of China). After washing with DDI water twice, the cells were mixed with a staining reagent for 60 minutes. The stained cells were imaged with an optical microscope (TE2000U; Nikon Corporation, Tokyo, Japan).

For the mineralization assay, the hMSCs $\left(3 \times 10^{4}\right.$ cells $\left./ \mathrm{mL}\right)$ were incubated in a 48-well plate with four substrates for 3 days. Then the culture medium was replaced by OIM. After 14 days in OIM, the mineralized matrix was stained for calcium with Alizarin red stain. ${ }^{48}$ Briefly, cells were washed with PBS and fixed in ice-cold $70 \%$ ethanol for 1 hour. Ethanol was removed, and the cells were rinsed with water and stained with $40 \mathrm{mM}$ Alizarin Red (pH 4.2) for 10 minutes at room temperature. The stained cells were rinsed five times with water, and then placed in PBS for 15 minutes to reduce nonspecific Alizarin Red stain. The stained cultures were photographed with an optical microscope (TE2000U).

\section{Adsorption and release assay}

To adsorb BMP-2 (PeproTech, Inc, Rocky Hill, NJ, USA) into the membranes, different membranes $(1 \mathrm{~cm} \times 1 \mathrm{~cm})$ were separately immersed in $1 \mathrm{~mL}$ of BMP-2/PBS solution $(500 \mu \mathrm{g} / \mathrm{mL})$ at room temperature for 4 hours with gentle shaking. The membranes were then washed three times with PBS and dried in a vacuum at room temperature for 48 hours. The PBS washing solution and the remaining immersion solution were collected after the samples had been removed. These leftover solutions were analyzed for the concentration of BMP-2, which was defined as unabsorbed BMP-2. The loading efficiency (denoted as $\% \mathrm{~L}$ ) was calculated from the formula:

$$
\% \mathrm{~L}=\frac{\begin{array}{l}
\text { Total amount of BMP-2 }(\mu \mathrm{g})- \\
\text { Unabsorbed BMP-2 }(\mu \mathrm{g})
\end{array}}{\text { Total amount of BMP-2 }(\mu \mathrm{g})} \times 100 .
$$

In order to study growth factor release, an identical amount of BMP-2 was first adsorbed into different membranes $(1 \mathrm{~cm} \times 1 \mathrm{~cm})$. Then, the BMP-2 loading samples were incubated in $2 \mathrm{~mL} \mathrm{PBS} / 1 \% \mathrm{BSA}$ buffer $\left(37^{\circ} \mathrm{C}\right)$ for 7 days with mild shaking ( $50 \mathrm{rpm})$. The buffer was collected $(200 \mu \mathrm{L}$ total) at different incubation times, then frozen and stored at $-80^{\circ} \mathrm{C}$. The collected release buffer was replenished using an equal volume of fresh PBS. At the end of the experiment, all collected samples were thawed and quantitatively analyzed using a human BMP-2 enzyme-linked immunosorbent assay kit (Sigma-Aldrich Co). This analysis was performed in triplicate for each time point with mean \pm SD values reported. Cumulative release is expressed as a percentage of total loaded protein.

\section{Results and discussion Characterization of the PLGA and PLGA-MBG membranes}

Scaffold porosity affects bone tissue regeneration. Generally, a high porosity with a high interconnection between the pores is required for cell ingrowth, vascularization, and the diffusion of nutrients and waste. ${ }^{47,48}$ The SEM data indicated that the PLGA and PLGA-MBG membranes were porous (Figure 1). All four groups of samples had porous structure (left column of images), while the enlarged area (right column of images) reveals that the surface roughness of nanofibers increased dramatically with the MBG percentage. The surface of the $\mathrm{P} 8$ composite nanofibers contained a dense layer of MBG particle aggregates.

Figure 2 shows the distribution of chemical composition on the P8 film surface. Strong signals for $\mathrm{Si}, \mathrm{Ca}, \mathrm{P}$, and $\mathrm{O}$ were detected in EDS maps corresponding to the areas covered with MBG, which indicated the existence of a Caand P-containing material in the PLGA-MBG membrane. Additionally, a strong carbon signal was detected in the PLGA film.

The presence of mesopores can be observed in TEM images (Figure 3A). This indicates that the areas of $\mathrm{MBG}$ coating had well-ordered pores. The Brunauer-EmmettTeller surface areas of P8 scaffolds were $521.3 \mathrm{~m}^{2} \mathrm{~g}^{-1}$. The P8 sample had a relatively narrow pore size distribution, with a median size of $5.6 \mathrm{~nm}$ (Barrett-Joyner-Halenda data; Figure 3B).

Surface hydrophilicity of the scaffolds influences the performance of biomaterials. Improved surface hydrophilicity promotes interactions between the polymer matrix and cells, which facilitates cell adhesion and growth. ${ }^{49}$ Herein, we studied the relative hydrophilicity of both PLGA and the composite scaffolds via a static contact angle measurement system (Figure 4). It is clear that the water contact angles fell sharply from $117.1^{\circ}$ for PLGA to $53.6^{\circ}$ for P2. The P4 

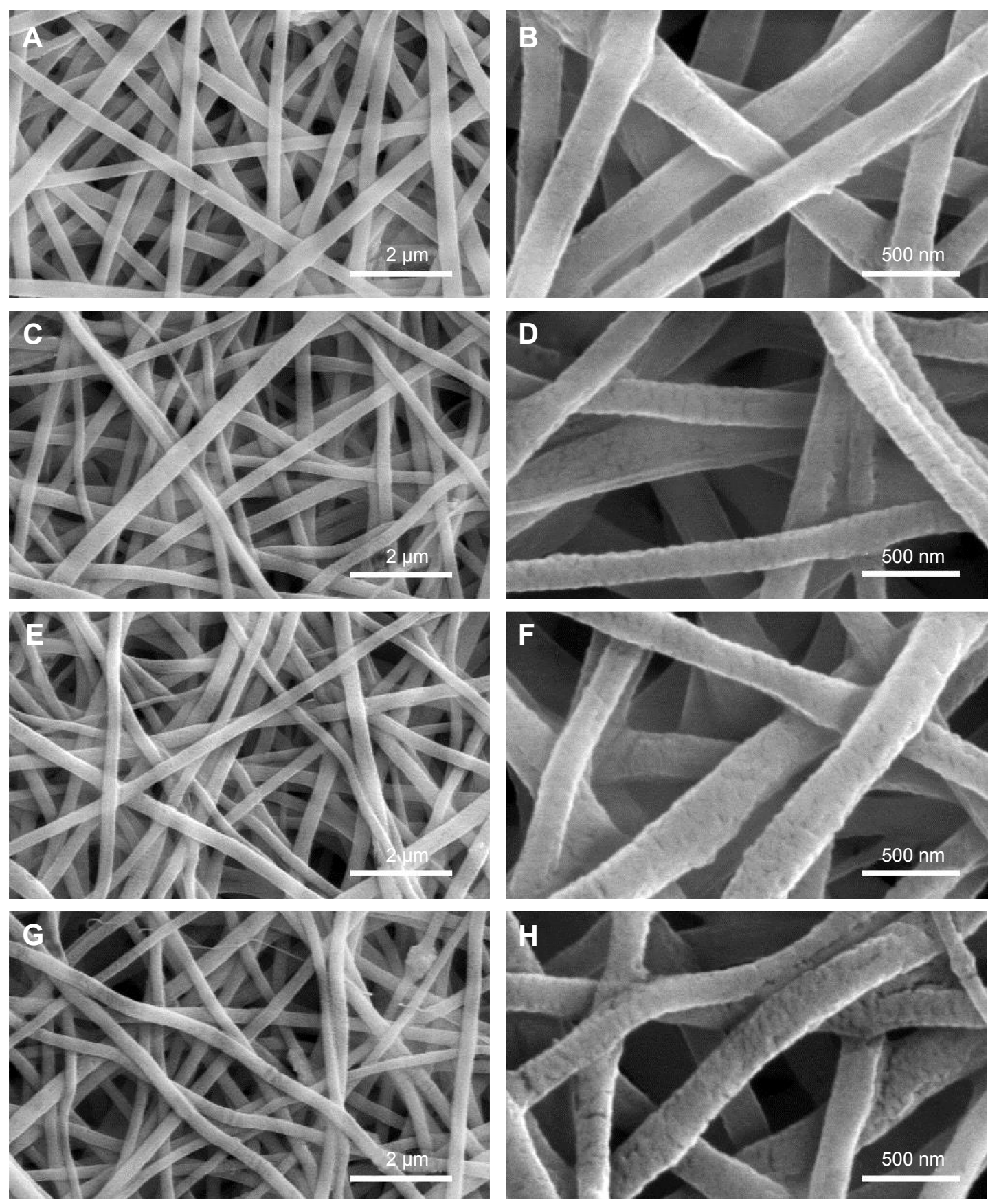

Figure I SEM images of the surface microstructures. (A and B: P0, C and D: P2, E and F: P4, G and H: P8).

Notes: P2, P4, or P8 represents the PLGA scaffold coated by MBG precursor solution for 2, 4, or 8 times, respectively. P0 represents the unmodified PLGA scaffold.

Abbreviations: SEM, scanning electron microscopy; MBG, mesoporous bioactive glass; PLGA, poly(lactic-co-glycolic acid).

and P8 samples had water contact angles of $50.3^{\circ}$ and $46.3^{\circ}$, respectively. This demonstrates that MBG coating markedly increases surface hydrophilicity.

\section{In vitro bioactivity}

The bioactive behavior of the scaffolds in the absence of cells was studied in vitro by immersing samples in SBF. Figure 5 shows the changes of the chemical composition on the surface of the four scaffolds, as observed by EDS spectra. No Ca or P formation was seen on the P0 scaffold, even after SBF treatment for 7 days (Figure 5A). However, after the same duration of immersion, $\mathrm{Ca}$ and $\mathrm{P}$ were seen on PLGA-MBG surfaces (Figure 5B-D). The $\mathrm{Ca} / \mathrm{P}$ ratios corresponded to values observed in the carbonated HAp deficient in calcium. These values were slightly lower than the 1.67 ratio seen in formal apatite. 

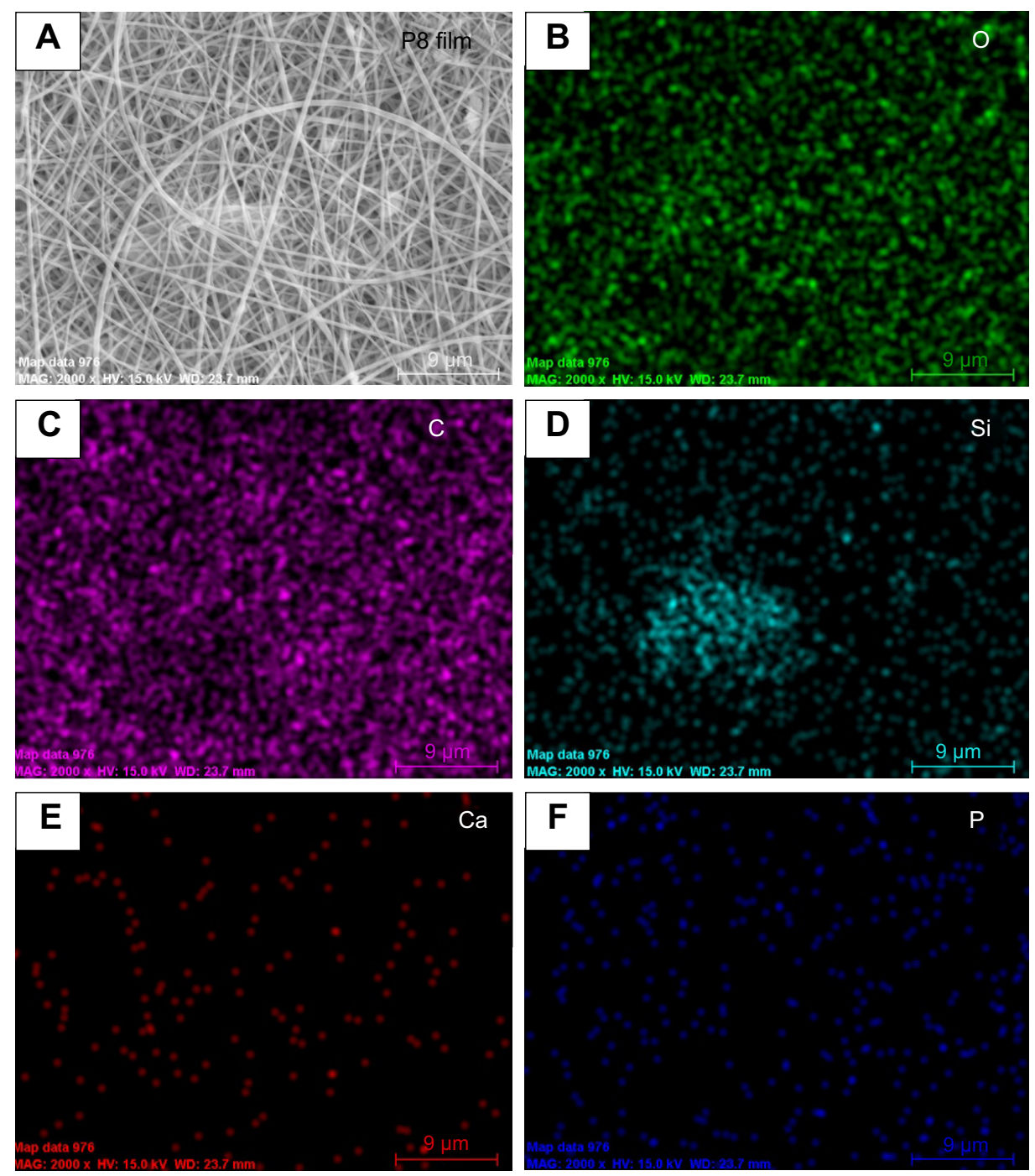

Figure 2 SEM image and EDAX mapping of P8 film surface.

Notes: (A) Surface morphology; (B-F) distribution of chemical composition respective for O, C, Si, Ca and P. P8 represents the PLGA scaffold coated by MBG precursor solution for 8 times.

Abbreviations: SEM, scanning electron microscopy; EDS, energy dispersive spectrometer; MBG, mesoporous bioactive glass; PLGA, poly(lactic-co-glycolic acid).

A

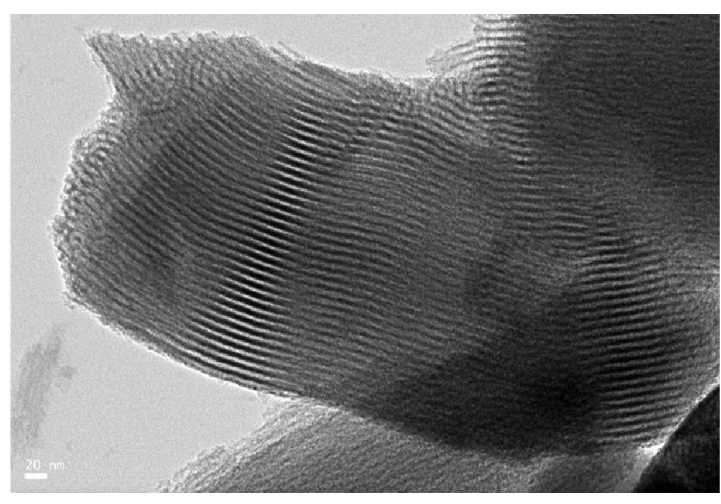

B

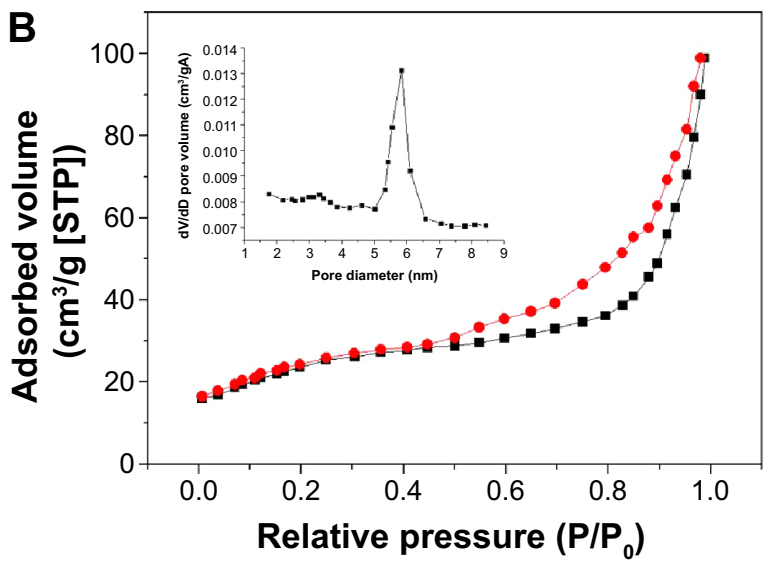

Figure 3 (A) TEM image of the surface microstructure and (B) N2 adsorption (black line)-desorption (red line) isotherms and corresponding pore size distributions (inset) of composite scaffold P8 after sufficient drying.

Note: P8 represents the PLGA scaffold coated by MBG precursor solution for 8 times.

Abbreviations: TEM, transmission electron microscopy; MBG, mesoporous bioactive glass; PLGA, poly(lactic-co-glycolic acid); STP, standard temperature and pressure. 

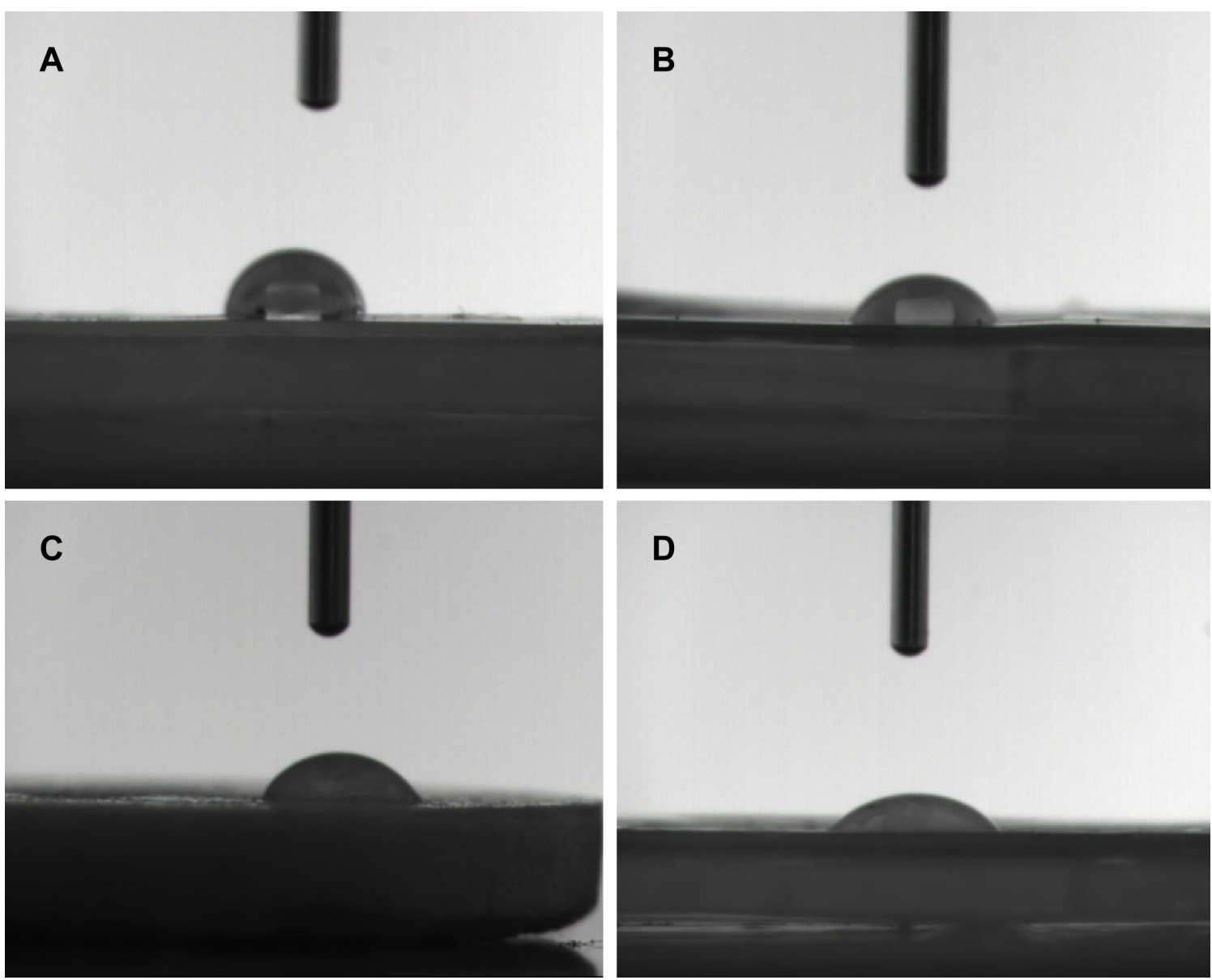

Figure 4 Hydrophilicity of the surface microstructures of (A) PLGA, P0, (B) P2, (C) P4, and (D) P8 composite scaffolds determined by contact angle test. Notes: P2, P4, or P8 represents the PLGA scaffold coated by MBG precursor solution for 2, 4, or 8 times, respectively. P0 represents the unmodified PLGA scaffold. Abbreviations: MBG, mesoporous bioactive glass; PLGA, poly(lactic-co-glycolic acid).

\section{Cell proliferation}

PLGA-MBG surfaces (P2, P4, and P8) favored the proliferation of hMSCs over the pure PLGA (P0) surface. After 3 days, cell growth significantly increased with MBG coating times (Figure 6). This increase may be associated with the improved hydrophilicity of the MBG surface-coated composite scaffolds. In addition, the PLGA-MBG scaffold had a larger surface area than the pure PLGA matrix. It is believed that the enhancement of the scaffold surface area may promote cell growth more efficiently than a bulk substrate. ${ }^{50}$ Similar results were observed in other studies showing that addition of MBG into the polymer matrix enhanced cell spreading and proliferation. ${ }^{43,51}$ Altogether, these data leave little doubt that MBG possesses excellent in vitro bioactivity.

\section{Differentiation of hMSCs on the surface of specimens}

ALP is an indicator of differentiation in osteoblast-like cells. ${ }^{52}$ We measured ALP in cells cultured with the four PLGA-based scaffolds after 3, 7, and 14 days of incubation. The hMSCs on the surface of the PLGA had significantly lower ALP activity than those cultured on the PLGA-MBG surface at days 7 and 14 ( $P<0.05$; Figure 7A). The ALP activity on day 7 for the hMSCs on the PLGA-MBG surfaces was higher, but no differences were seen between the P2, P4, and P8 samples. Notably, the hMSCs cultivated for 14 days on the P8 PLGAMBG scaffold had significantly higher ALP activity levels than those cultivated on the other PLGA-MBG scaffolds $(P<0.05)$. Figure 7B shows positive ALP staining on the four PLGA-based scaffolds at day 14. Staining on the PLGA-MBG surfaces was much denser than on the PLGA-only surface. A key function of osteogenic cells is mineralization. We assessed calcium deposition by osteogenic cells via Alizarin Red staining at day 14 (Figure 8). While the level of mineralization on the $\mathrm{P} 2$ and $\mathrm{P} 4$ surfaces was lower than on the $\mathrm{P} 8$ surfaces, it was still higher than the levels seen on the P0 surfaces.

\section{Protein adsorption and release}

BMP-2 is clinically useful, but requires high doses and produces a relatively weak response in hMSCs. This leads to 
A
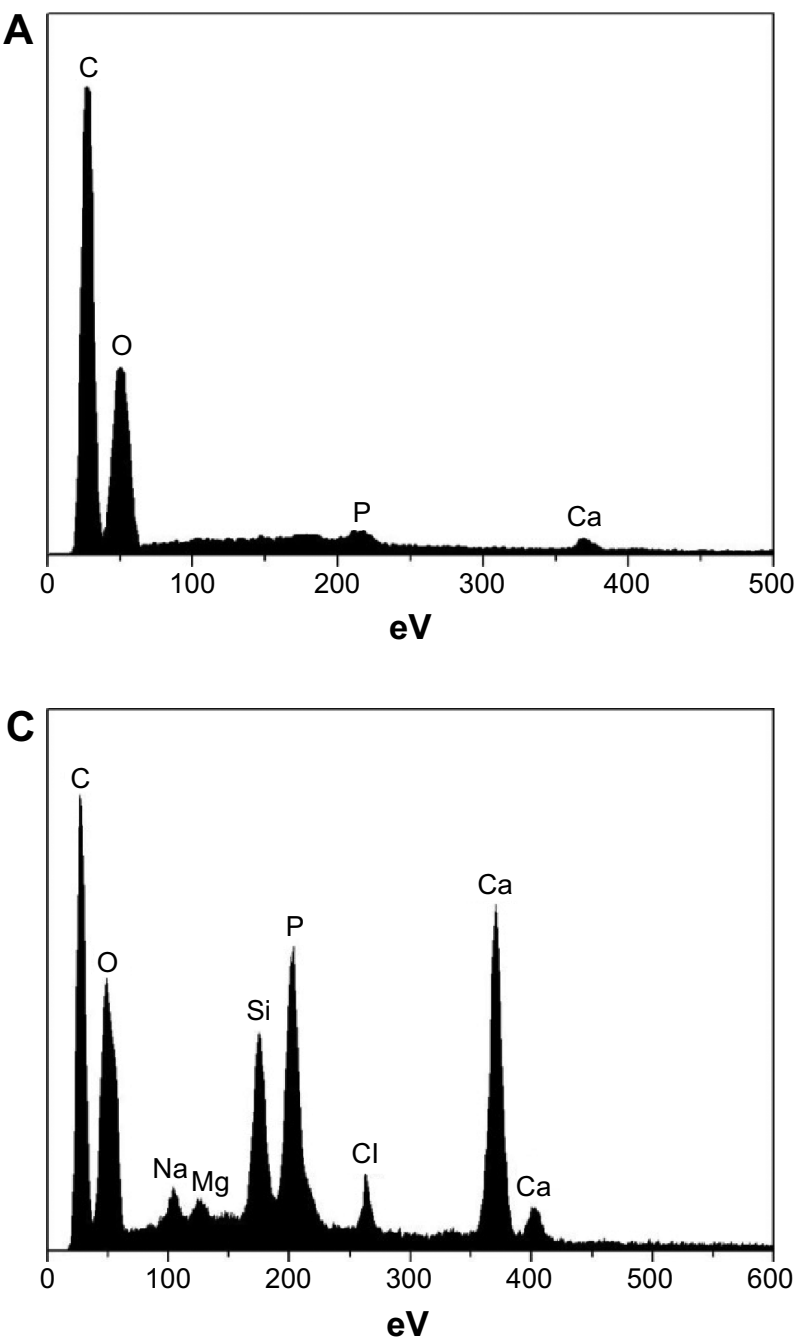

B

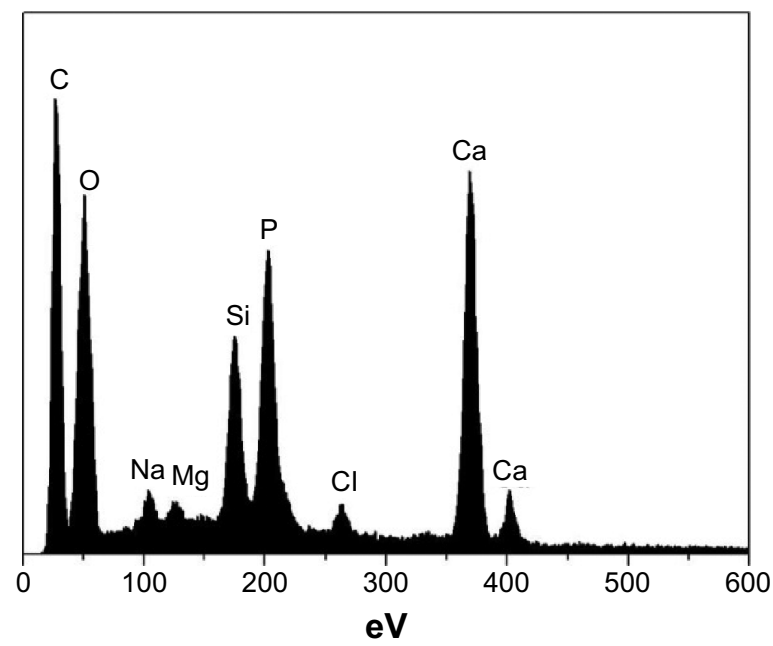

D

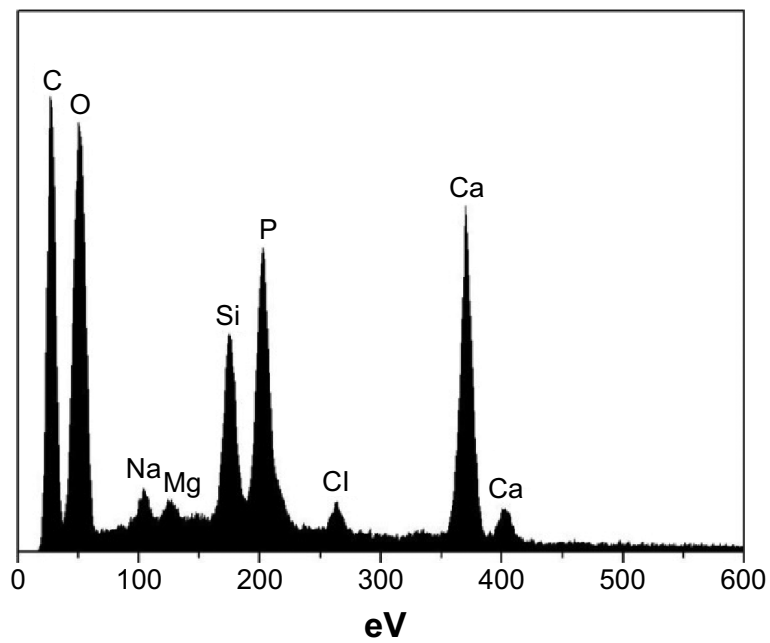

Figure 5 EDS spectra of scaffolds after being immersed in SBF for 7 days. (A: PLGA, P0, B: P2, C: P4, and D: P8).

Notes: P2, P4, or P8 represents the PLGA scaffold coated by MBG precursor solution for 2, 4, or 8 times, respectively. P0 represents the unmodified PLGA scaffold. Abbreviations: EDS, energy dispersive spectrometer; MBG, mesoporous bioactive glass; PLGA, poly(lactic-co-glycolic acid).

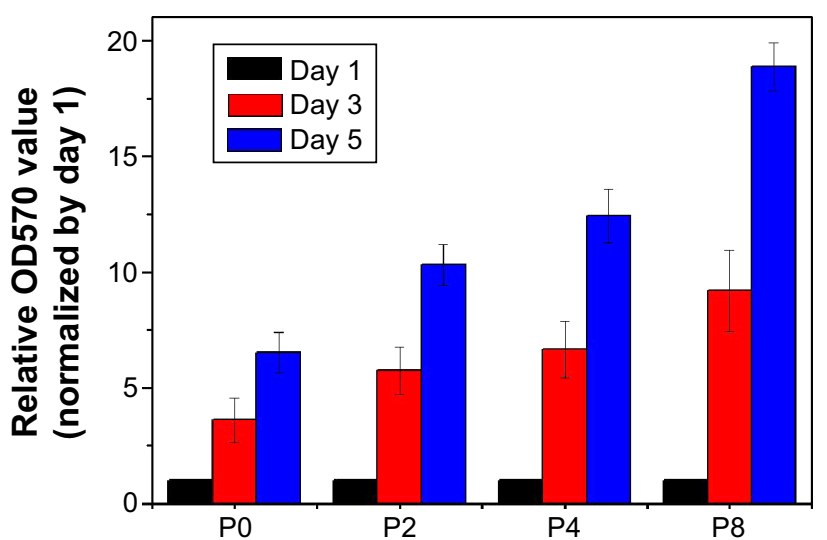

Figure 6 Cell proliferation of hMSCs incubated on samples after I, 3 and 5 days. Notes: P2, P4, or P8 represents the PLGA scaffold coated by MBG precursor solution for 2, 4, or 8 times, respectively. P0 represents the unmodified PLGA scaffold. Abbreviations: hMSCs, human mesenchymal stem cells; MBG, mesoporous bioactive glass; PLGA, poly(lactic-co-glycolic acid). an increase in both costs and side effects. ${ }^{53,54}$ Therefore, the controlled release of BMPs could radically improve bone tissue engineering. In our current study, MBG-coated PLGA scaffolds increased the adsorption of BMP-2 and allowed for the controlled release of BMP-2 from scaffolds. This increased the efficiency of BMP-2 usage. The loading efficiency of BMP-2 on PLGA-MBG scaffolds was tuned using MBG and was 35\% in $\mathrm{P} 2,51 \%$ in $\mathrm{P} 4$, and $69 \%$ in $\mathrm{P} 8$ samples. The $\mathrm{P} 0$ samples had significantly lower loading efficiency at only $6.8 \%$. The release of BMP-2 is shown in Figure 9. A nearly complete release of BMP-2 was observed from the PLGA scaffold after only 2 days. All three PLGA-MBG scaffolds had similar release behavior. There is a two-step release process: an initial burst release followed by a relatively slow release. Following the MBG coating, approximately $70 \%, 52 \%$, and $35 \%$ of the total 


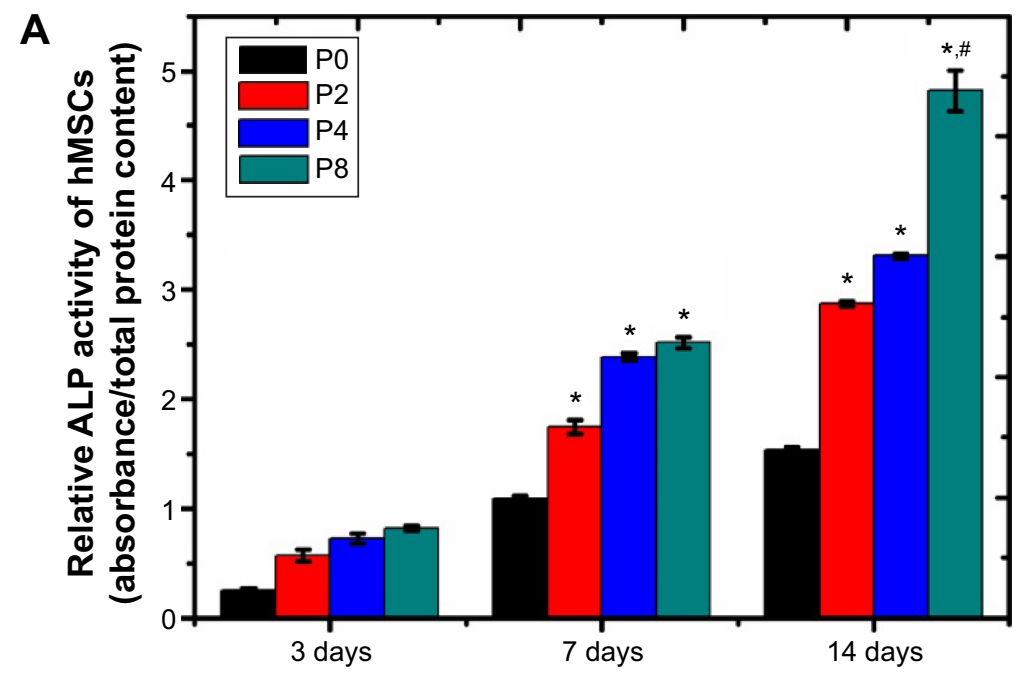

B
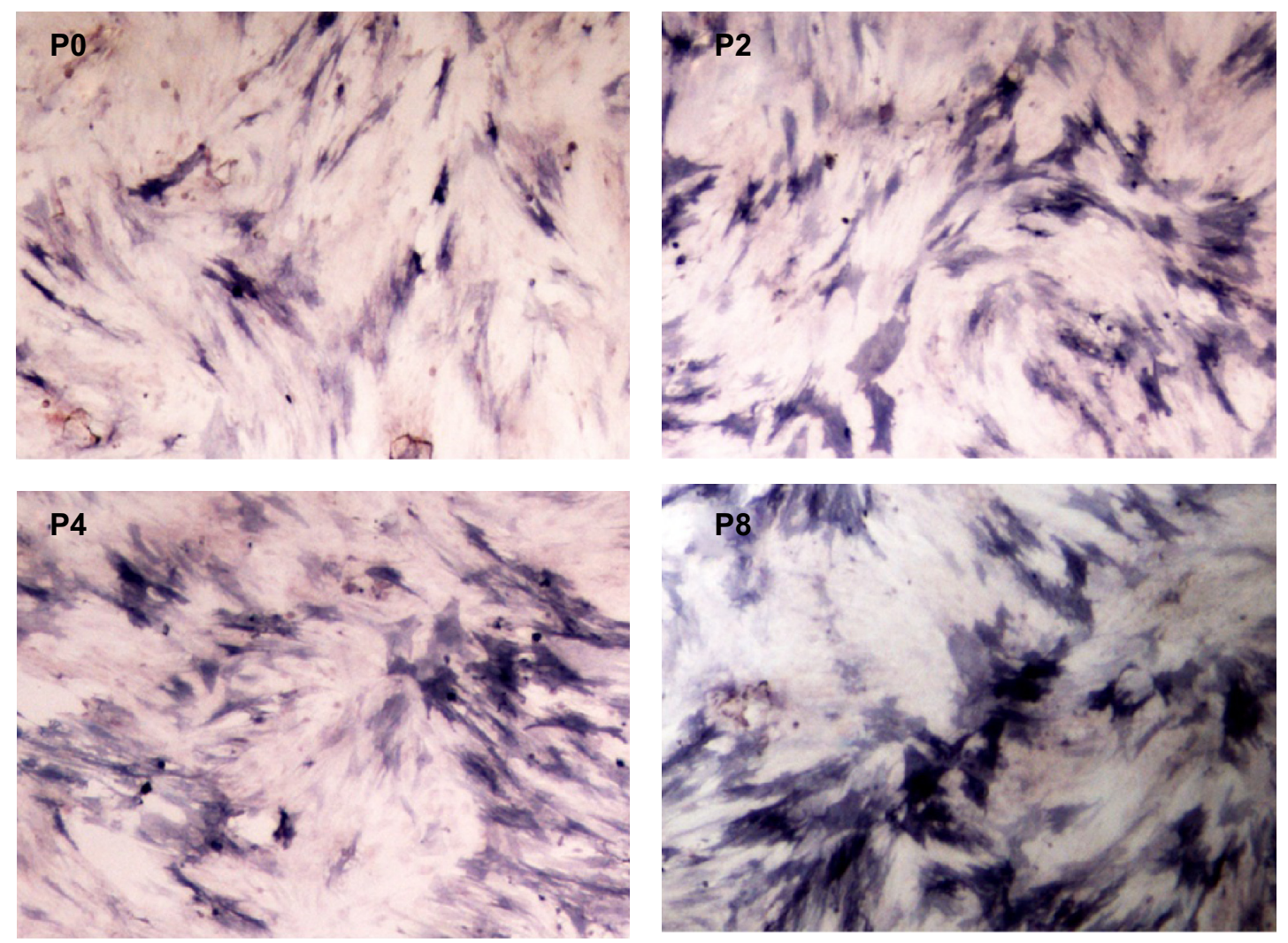

Figure 7 ALP activity and ALP staining assay.

Notes: (A) Relative ALP activity of hMSCs after 3,7 , and 14 days of co-culture with different samples $\left(* P<0.05\right.$, compared to $P 0$ at the same time; ${ }^{*} P<0.05$, compared to other scaffolds at the same time). (B) Images of positive ALP staining. The hMSCs were stained after being cultured with the four scaffolds respectively for I4 days. P2, P4, or P8 represents the PLGA scaffold coated by MBG precursor solution for 2, 4, or 8 times, respectively. P0 represents the unmodified PLGA scaffold.

Abbreviations: hMSCs, human mesenchymal stem cells; ALP, alkaline phosphatase; MBG, mesoporous bioactive glass; PLGA, poly(lactic-co-glycolic acid).

BMP-2 was released in the first 48 hours for P2, P4, and P8 samples, respe-ctively. After 7 days, the amount of released BMP-2 reached $82 \%, 69 \%$, and $56 \%$ for $\mathrm{P} 2$, P4, and $\mathrm{P} 8$ scaffolds, respectively.

Thus, the BMP-2 release rate from the PLGA-MBG scaffolds is much lower than that seen with PLGA only. It is also more controlled via MBG. These data show that MBG can increase the adsorption of protein due to the high surface area of the MBGs. Moreover, BMP-2 molecules contain hydroxyl groups and amino groups that form hydrogen bonds with the Si-OH groups on the MBGs. The sustained release of BMP-2 from the scaffolds may facilitate the regeneration of 

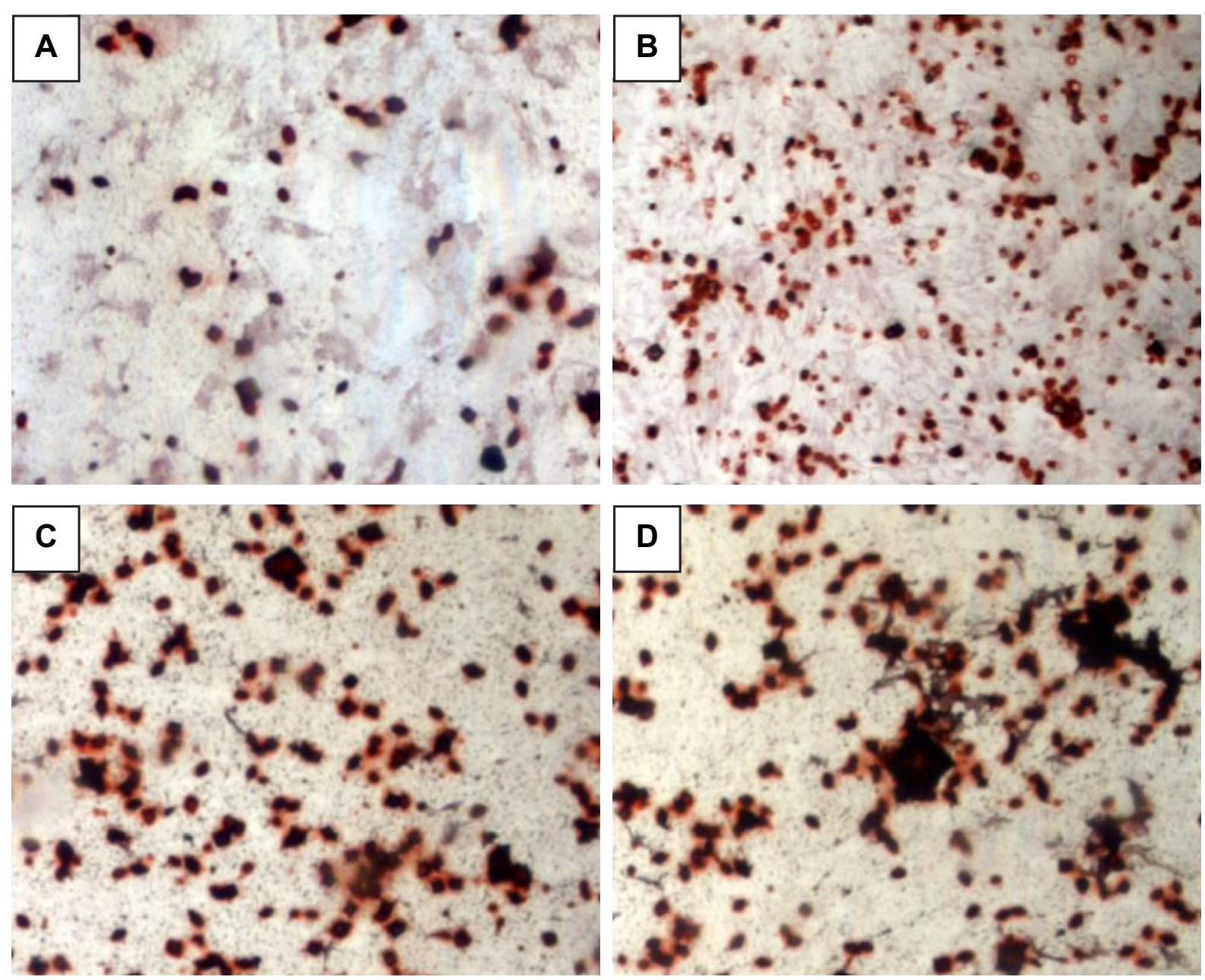

Figure 8 Mineralization (Alizarin red staining) assay. (A: PLGA, P0, B: P2, C: P4, and D: P8).

Notes: P2, P4, or P8 represents the PLGA scaffold coated by MBG precursor solution for 2, 4, or 8 times, respectively. P0 represents the unmodified PLGA scaffold. Abbreivations: MBG, mesoporous bioactive glass; PLGA, poly(lactic-co-glycolic acid).

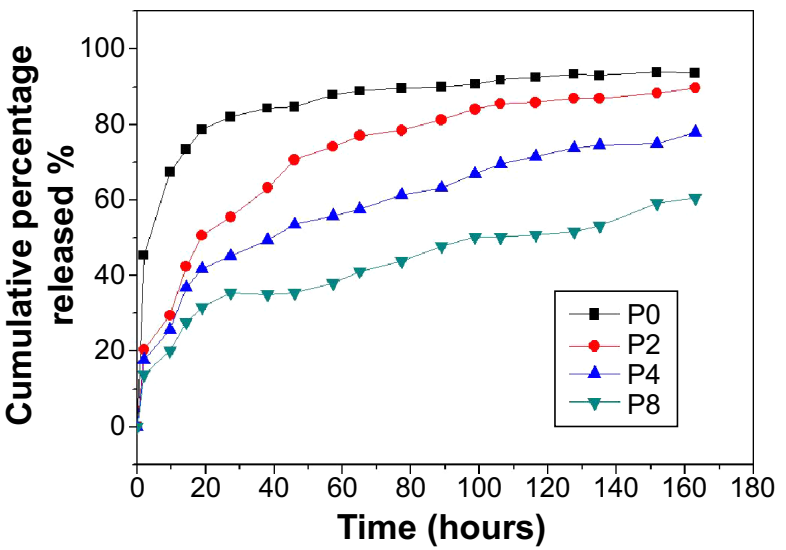

Figure 9 BMP-2 release profiles from PLGA and PLGA-MBG scaffolds with $20 \mu \mathrm{g}$ BMP-2 adsorption. The amount of BMP-2 released from scaffolds was determined by ELISA.

Notes: P2, P4, or P8 represents the PLGA scaffold coated by MBG precursor solution for 2, 4, or 8 times, respectively. P0 represents the unmodified PLGA scaffold.

Abbreviations: BMP-2, bone morphogenetic protein-2; MBG, mesoporous bioactive glass; PLGA, poly(lactic-co-glycolic acid); ELISA, enzyme-linked immunosorbent assay. functional bone tissue. Many studies have confirmed that sustained release of BMP-2 promotes new bone formation. ${ }^{55-57}$ In previous research, the release rate of BMP-2 was tuned via $\mathrm{MBG}$, and the sustained release resulted in the formation of mature bone..$^{58}$

Following surface modification, mesoporous structure was successfully introduced into the PLGA-MBG fibrous scaffold. According to the results of in vitro bioactivity, cell viability and differentiation assays, it was confirmed that MBG incorporation allows for the composite PLGA fibrous scaffold to promote biological properties (Figure 10). Moreover, a synergetic reaction takes place on the PLGA-MBG scaffold. On one hand, the modified surface attracts hMSCs to adhere onto the scaffold. Yet, on the other hand, the modified surface dramatically enhances BMP-2 adsorption and provides a sustained release. The adsorbed BMP-2 on the scaffold could effectively aid the proliferation and osteogenic 


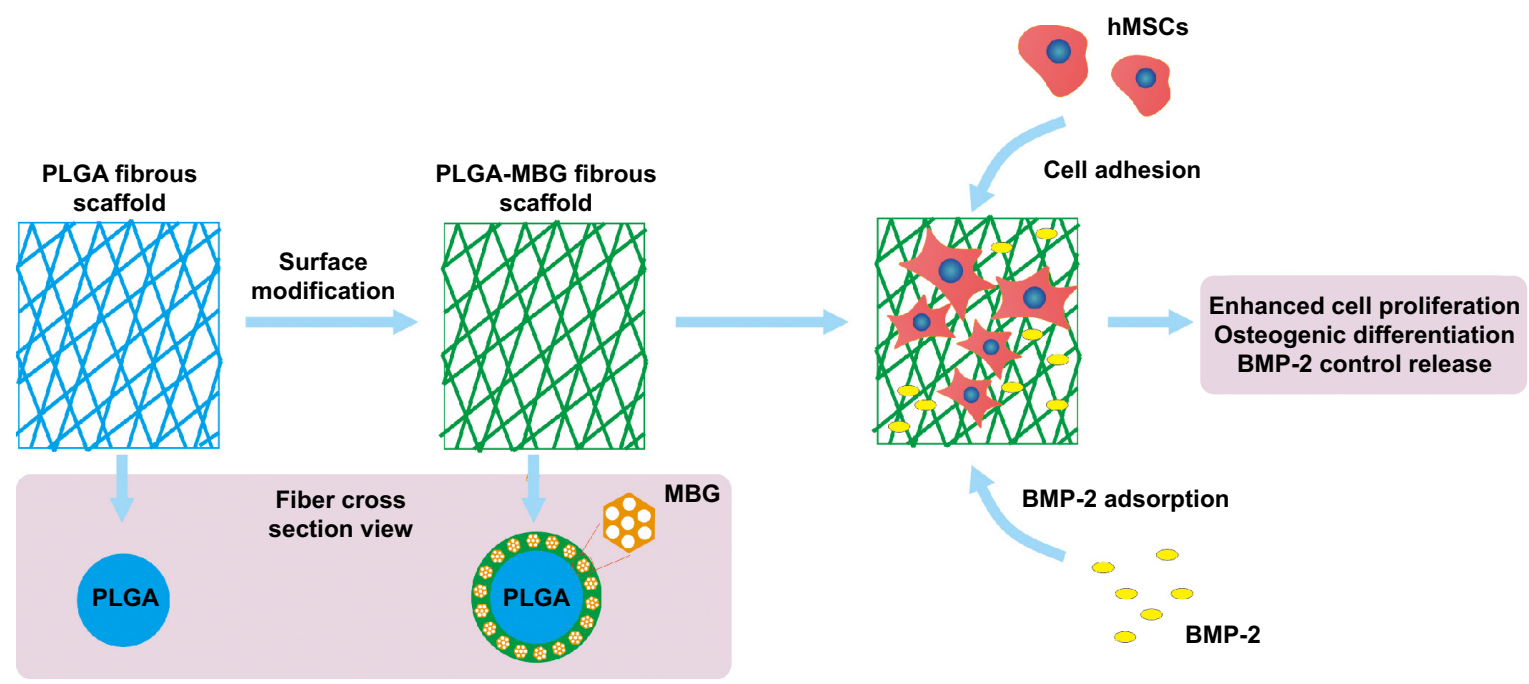

Figure 10 Microstructure and promoted biological properties of PLGA-MBG scaffold. Abbreviations: MBG, mesoporous bioactive glass; PLGA, poly(lactic-co-glycolic acid).

differentiation of hMSCs. As a result, the PLGA-MBG fibrous scaffold may induce enhanced mineralization.

In addition, it was found that inorganic materials such as HAp and BG can be used to effectively compensate for the pH decrease induced by PLGA degradation. ${ }^{33}$ Although we did not investigate the degradation of the PLGA-MBG fibrous scaffold and the related $\mathrm{pH}$ changes, it had been evidenced that the incorporation of MBG into PLGA resulted in a more stable $\mathrm{pH}$ of the surrounding biological medium. With the increase of MBG contents in the PLGA film, the $\mathrm{pH}$ value of SBF was maintained at 6.5 7.0 for up to 70 days of soaking. In comparison, the $\mathrm{pH}$ value of $\mathrm{SBF}$ rapidly decreased after 21 days of soaking of the pure PLGA film. ${ }^{33}$ Consequently, it was hypothesized that the released $\mathrm{Ca}$ and $\mathrm{Si}$ ions from our PLGA-MBG fibrous scaffold might neutralize the acidic degradation products of PLGA and thus compensate for the decrease in $\mathrm{pH}$ value. Hence, a PLGA-MBG fibrous scaffold might be a better alternative for avoiding the inflammation aroused by PLGA degradation.

\section{Conclusion}

In the present study, MBG surface-modified PLGA composite scaffolds were prepared through a combination of electrospinning and surface doping. The MBG coating improved surface hydrophilicity. More apatite is formed on the surfaces of PLGA-MBG composite scaffolds after 7 days of immersion in SBF than in PLGA-only scaffolds. This implies that the MBG coating improved the bioactivity of the scaffold. In addition, the MBG coating promoted the attachment and proliferation of hMSCs, which may be associated with the mesoporous structure and MBG content of the composite scaffolds. Furthermore, PLGA-MBG composite scaffolds showed enhanced controllable release of BMP-2. In conclusion, the physicochemical and biological properties of the MBG-coated PLGA composite scaffolds are suitable for bone repair therapeutics after further validation.

\section{Acknowledgments}

This work was supported by Fundamental Research Funds for the Central Universities (grant number 2012QNZT126) as well as the Foundation of Development and Reform Commission of Hunan Province (grant number 2014-685-CSU).

\section{Disclosure}

The authors report no conflicts of interest in this work.

\section{References}

1. Cordonnier T, Sohier J, Rosset P, Layrolle P. Biomimetic materials for bone tissue engineering-state of the art and future trends. Adv Eng Mater. 2011;13(5):B135-B150.

2. Weatherholt AM, Fuchs RK, Warden SJ. Specialized connective tissue: bone, the structural framework of the upper extremity. $J$ Hand Ther 2012;25(2):123-132.

3. Finkemeier CG. Bone-grafting and bone-graft substitutes. $J$ Bone Joint Surg Am. 2002;84-A(3):454-464.

4. Greenwald AS, Boden SD, Goldberg VM, Khan Y, Laurencin CT, Rosier RN; American Academy of Orthopaedic Surgeons; The Committee on Biological Implants. Bone-graft substitutes: facts, fictions, and applications. J Bone Joint Surg Am. 2001;83-ASuppl 2 Pt 2:S98-S103.

5. Gao C, Deng Y, Feng P, et al. Current progress in bioactive ceramic scaffolds for bone repair and regeneration. Int J Mol Sci. 2014;15(3): 4714-4732.

6. Dahlin C, Johansson A, Hoffman M, Molenberg A. Early biocompatibility of poly(ethylene glycol) hydrogel barrier materials for guided bone regeneration. An in vitro study using human gingival fibroblasts (HGF-1). Clin Oral Implants Res. 2014;25(1):16-20. 
7. Hickman GJ, Rees RC, Boocock DJ, Pockley AG, Perry CC. Controlling the dynamics of cell transition in heterogeneous cultures using surface chemistry. Adv Healthc Mater. 2015;4(4):593-601.

8. Shen Y, Gao M, Ma Y, et al. Effect of surface chemistry on the integrin induced pathway in regulating vascular endothelial cells migration. Colloids Surf B Biointerfaces. 2015;126:188-197.

9. Stevens MM, George JH. Exploring and engineering the cell surface interface. Science. 2005;310(5751):1135-1138.

10. Delaine-Smith RM, Green NH, Matcher SJ, MacNeil S, Reilly GC. Monitoring fibrous scaffold guidance of three-dimensional collagen organisation using minimally-invasive second harmonic generation. PloS One. 2014;9(2):e89761.

11. Gentile P, Chiono V, Carmagnola I, Hatton PV. An overview of poly (lactic-co-glycolic) acid (PLGA)-based biomaterials for bone tissue engineering. Int J Mol Sci. 2014;15(3):3640-3659.

12. Chung YI, Kim JC, Kim YH, et al. The effect of surface functionalization of PLGA nanoparticles by heparin- or chitosanconjugated Pluronic on tumor targeting. J Control Release. 2010;143(3): 374-382.

13. Jose MV, Thomas V, Johnson KT, Dean DR, Nyairo E. Aligned PLGA/ HA nanofibrous nanocomposite scaffolds for bone tissue engineering. Acta Biomater. 2009;5(1):305-315.

14. Kong C, Lee T, Lee S, Kim HS. Nano-web formation by the electrospinning at various electric fields. J Mater Sci. 2007;42(19): 8106-8112.

15. De Vrieze S, Westbroek P, Van Camp T, De Clerck K. Solvent system for steady state electrospinning of polyamide 6.6. J Appl Polym Sci. 2010;115(2):837-842.

16. Wang Y, Li H, Wang G, Yin T, Wang B, Yu Q. Electrospinning of polymer nanofibers with ordered patterns and architectures. J Nanosci Nanotechnol. 2010;10(3):1699-1706.

17. Duan B, Yuan X, Zhu Y, et al. A nanofibrous composite membrane of PLGA-chitosan/PVA prepared by electrospinning. Eur Polym J. 2006; 42(9):2013-2022.

18. Min BM, You Y, Kim JM, Lee SJ, Park WH. Formation of nanostructured poly(lactic-co-glycolic acid)/chitin matrix and its cellular response to normal human keratinocytes and fibroblasts. Carbohydr Polym. 2004;57(3):285-292.

19. Meng ZX, Wang YS, Ma C, Zheng W, Li L, Zheng YF. Electrospinning of PLGA/gelatin randomly-oriented and aligned nanofibers as potential scaffold in tissue engineering. Mater Sci Eng C Mater Biol Appl. 2010;30(8):1204-1210.

20. Wu C, Zhang Y, Fan W, et al. $\mathrm{CaSiO}_{3}$ microstructure modulating the in vitro and in vivo bioactivity of poly(lactide-co-glycolide) microspheres. J Biomed Mater Res A. 2011;98(1):122-131.

21. Zhao L, Lin K, Zhang M, et al. The influences of poly(lactic-coglycolic acid) (PLGA) coating on the biodegradability, bioactivity, and biocompatibility of calcium silicate bioceramics. J Mater Sci. 2011; 46(14):4986-4993.

22. Zhao L, Wu C, Lin K, Chang J. The effect of poly(lactic-co-glycolic acid) (PLGA) coating on the mechanical, biodegradable, bioactive properties and drug release of porous calcium silicate scaffolds. Biomed Mater Eng. 2012;22(5):289-300.

23. Makadia HK, Siegel SJ. Poly lactic-co-glycolic acid (PLGA) as biodegradable controlled drug delivery carrier. Polymers (Basel). 2011;3(3): 1377-1397.

24. Hild N, Tawakoli PN, Halter JG, et al. pH-dependent antibacterial effects on oral microorganisms through pure PLGA implants and composites with nanosized bioactive glass. Acta Biomater. 2013;9(11): 9118-9125.

25. Liu G, Wu C, Fan W, et al. The effects of bioactive akermanite on physiochemical, drug-delivery, and biological properties of poly(lactideco-glycolide) beads. J Biomed Mater Res B Appl Biomater. 2011;96(2): 360-368.

26. Tai IC, Fu YC, Wang CK, Chang JK, Ho ML. Local delivery of controlled-release simvastatin/PLGA/HAp microspheres enhances bone repair. Int J Nanomedicine. 2013;8:3895-3904.
27. Tang G, Zhang H, Zhao Y, Li X, Yuan X, Wang M. Prolonged release from PLGA/HAp scaffolds containing drug-loaded PLGA/ gelatin composite microspheres. J Mater Sci Mater Med. 2012;23(2): 419-429.

28. Kim J, McBride S, Tellis B, et al. Rapid-prototyped PLGA/ $\beta-T C P /$ hydroxyapatite nanocomposite scaffolds in a rabbit femoral defect model. Biofabrication. 2012;4(2):025003.

29. Yoshida T, Miyaji H, Otani K, et al. Bone augmentation using a highly porous PLGA/ $\beta$-TCP scaffold containing fibroblast growth factor-2. J Periodontal Res. 2015;50(2):265-273.

30. Shim JH, Yoon MC, Jeong CM, et al. Efficacy of rhBMP-2 loaded $\mathrm{PCL} / \mathrm{PLGA} / \beta-\mathrm{TCP}$ guided bone regeneration membrane fabricated by $3 \mathrm{D}$ printing technology for reconstruction of calvaria defects in rabbit. Biomed Mater. 2014;9(6):065006.

31. Filipowska J, Pawlik J, Cholewa-Kowalska K, et al. Incorporation of sol-gel bioactive glass into PLGA improves mechanical properties and bioactivity of composite scaffolds and results in their osteoinductive properties. Biomed Mater. 2014;9(6):065001.

32. Nazemi K, Azadpour P, Moztarzadeh F, Urbanska AM, Mozafari M. Tissue-engineered chitosan/bioactive glass bone scaffolds integrated with PLGA nanoparticles: a therapeutic design for on-demand drug delivery. Mater Lett. 2015;138:16-20.

33. Wu C, Ramaswamy Y, Zhu Y, et al. The effect of mesoporous bioactive glass on the physiochemical, biological and drug-release properties of poly(DL-lactide-co-glycolide) films. Biomaterials. 2009;30(12): 2199-2208.

34. Wu C, Zhou Y, Fan W, et al. Hypoxia-mimicking mesoporous bioactive glass scaffolds with controllable cobalt ion release for bone tissue engineering. Biomaterials. 2012;33(7):2076-2085.

35. Yan X, Huang X, Yu C, et al. The in-vitro bioactivity of mesoporous bioactive glasses. Biomaterials. 2006;27(18):3396-3403.

36. Izquierdo-Barba I, Ruiz-González L, Doadrio JC, González-Calbet JM, Vallet-Regí M. Tissue regeneration: a new property of mesoporous materials. Solid State Sci. 2005;7(8):983-989.

37. Wu C, Zhang Y, Zhu Y, Friis T, Xiao Y. Structure-property relationships of silk-modified mesoporous bioglass scaffolds. Biomaterials. 2010;31(13):3429-3438.

38. Trejo CG, Lozano D, Manzano M, et al. The osteoinductive properties of mesoporous silicate coated with osteostatin in a rabbit femur cavity defect model. Biomaterials. 2010;31(33):8564-8573.

39. Wei G, Jin Q, Giannobile WV, Ma PX. Nano-fibrous scaffold for controlled delivery of recombinant human PDGF-BB. $J$ Control Release. 2006;112(1):103-110.

40. Dimitriou R, Jones E, McGonagle D, Giannoudis PV. Bone regeneration: current concepts and future directions. BMC Med. 2011;9:66.

41. Wu C, Chang J. Multifunctional mesoporous bioactive glasses for effective delivery of therapeutic ions and drug/growth factors. J Control Release. 2014;193:282-295.

42. Dai C, Guo H, Lu J, Shi J, Wei J, Liu C. Osteogenic evaluation of calcium/magnesium-doped mesoporous silica scaffold with incorporation of rhBMP-2 by synchrotron radiation-based $\mu$ CT. Biomaterials. 2011; 32(33):8506-8517.

43. Zhou $\mathrm{P}$, Cheng X, Xia Y, et al. Organic/inorganic composite membranes based on poly(L-lactic-co-glycolic acid) and mesoporous silica for effective bone tissue engineering. Acs Appl Mater Interfaces. 2014; 6(23):20895-20903.

44. Zhu M, Zhang L, He Q, Zhao J, Limin G, Shi J. Mesoporous bioactive glass-coated poly(l-lactic acid) scaffolds: a sustained antibiotic drug release system for bone repairing. J Mater Chem. 2011;21(4): 1064-1072.

45. Janitabar-Darzi S. Structural and photocatalytic activity of mesoporous N-doped $\mathrm{TiO} 2$ with band-to-band visible light absorption ability. Particulate Science and Technology: An International Journal. 2014;32(5):506-511.

46. Kokubo T, Kushitani H, Sakka S, Kitsugi T, Yamamuro T. Solutions able to reproduce in vivo surface-structure changes in bioactive glassceramic A-W. J Biomed Mater Res. 1990;24(6):721-734. 
47. Duan B, Yuan X, Zhu Y, et al. A nanofibrous composite membrane of PLGA-chitosan/PVA prepared by electrospinning. Eur Polym J. 2006;42(9):2013-2022.

48. Stanford CM, Jacobson PA, Eanes ED, Lembke LA, Midura RJ. Rapidly forming apatitic mineral in an osteoblastic cell line (UMR 106-01 BSP). J Biol Chem. 1995;270(16):9420-9428.

49. Danilevicius P, GeorgiadiL, PatemanCJ,ClaeyssensF, ChatzinikolaidouM, Farsari M. The effect of porosity on cell ingrowth into accurately defined, laser-made, polylactide-based 3D scaffolds. Appl Surf Sci. 2015; 336:1-10.

50. Krishnan L, Touroo J, Reed R, Boland E, Hoying JB, Williams SK. Vascularization and cellular isolation potential of a novel electrospun cell delivery vehicle. J Biomed Mater Res A. 2014;102(7): 2208-2219.

51. Shi C, Yuan W, Khan M, et al. Hydrophilic PCU scaffolds prepared by grafting PEGMA and immobilizing gelatin to enhance cell adhesion and proliferation. Mater Sci Eng C Mater Biol Appl. 2015;50:201-209.

52. Kraus D, Deschner J, Jäger A, et al. Human $\beta$-defensins differently affect proliferation, differentiation, and mineralization of osteoblast-like MG63 cells. J Cell Physiol. 2012;227(3):994-1003.
53. Mikulska A, Filipowska J, Osyczka AM, Nowakowska M, Szczubiałka K. Osteoinductive activity of insulin-functionalized cell culture surfaces obtained using diazonium chemistry. Front Chem. 2015;2:117.

54. Wang Z, Wang K, Lu X, et al. BMP-2 encapsulated polysaccharide nanoparticle modified biphasic calcium phosphate scaffolds for bone tissue regeneration. J Biomed Mater Res A. 2015;103(4):1520-1532.

55. Phipps MC, Clem WC, Grunda JM, Clines GA, Bellis SL. Increasing the pore sizes of bone-mimetic electrospun scaffolds comprised of polycaprolactone, collagen I and hydroxyapatite to enhance cell infiltration. Biomaterials. 2012;33(2):524-534.

56. Rahman CV, Ben-David D, Dhillon A, et al. Controlled release of BMP-2 from a sintered polymer scaffold enhances bone repair in a mouse calvarial defect model. J Tissue Eng Regen Med. 2014;8(1):59-66.

57. Seo BB, Choi H, Koh JT, Song SC. Sustained BMP-2 delivery and injectable bone regeneration using thermosensitive polymeric nanoparticle hydrogel bearing dual interactions with BMP-2.J Control Release. 2015;209:67-76

58. Zhang Q, Zhang Y, Chen W, Zhang B, Wang S. Long-term controlled release of 125I-tagged BMP-2 by mesoporous bioactive glass with ordered nanopores. Exp Ther Med. 2013;6(6):1443-1448.
International Journal of Nanomedicine

\section{Publish your work in this journal}

The International Journal of Nanomedicine is an international, peerreviewed journal focusing on the application of nanotechnology in diagnostics, therapeutics, and drug delivery systems throughout the biomedical field. This journal is indexed on PubMed Central, MedLine, CAS, SciSearch $®$, Current Contents $\AA /$ Clinical Medicine,

\section{Dovepress}

Journal Citation Reports/Science Edition, EMBase, Scopus and the Elsevier Bibliographic databases. The manuscript management system is completely online and includes a very quick and fair peer-review system, which is all easy to use. Visit http://www.dovepress.com/ testimonials.php to read real quotes from published authors. 